\title{
Production of nanoporous carbons from wood processing wastes and their use
} in supercapacitors and $\mathrm{CO}_{2}$ capture

\author{
G. Dobele ${ }^{\text {a }}$, T. Dizhbite ${ }^{\text {a }}$, M.V. Gil ${ }^{\text {b }}$, A. Volpert ${ }^{\text {a }}$, T.A. Centeno $^{\text {b, * }}$ \\ ${ }^{a}$ Latvian State Institute of Wood Chemistry, 27 Dzerbenes St., 1006 Riga, Latvia \\ ${ }^{\mathrm{b}}$ Instituto Nacional del Carbón -CSIC, Apartado 73, 33080 Oviedo, Spain
}

\begin{abstract}
Highly porous carbons were obtained from solid wastes generated in the chemical and the mechanical processing of birch wood (substandard kraft cellulose, hydrolysis lignin, chips and bark). $\mathrm{NaOH}$-chemical activation of these residues at 575 $800^{\circ} \mathrm{C}$ resulted in an efficient process to produce carbons with specific surface areas well above $1000 \mathrm{~m}^{2} \mathrm{~g}^{-1}$ and average pore widths of $1-1.7 \mathrm{~nm}$.

Comparative evaluations have shown the potentiality of wood wastes-based carbons in applications related to environmental protection. Activated carbons derived from chips- and bark-birch wood displayed specific capacitances as high as $308 \mathrm{Fg}^{-1}$ in the $\mathrm{H}_{2} \mathrm{SO}_{4}$ aqueous electrolyte and $200 \mathrm{Fg}^{-1}$ in the $\left(\mathrm{C}_{2} \mathrm{H}_{5}\right)_{4} \mathrm{NBF}_{4}$ /acetonitrile organic medium. Moreover, their capacitive performance at high current density competed well with that found for commercial carbons used in supercapacitors.

Wood-derived carbons also proved to be highly promising for $\mathrm{CO}_{2}$ capture in power stations, achieving uptakes under post- and pre-combustion conditions of 11-16 wt. $\%$ and 49-91 wt.\%, respectively.
\end{abstract}

Keywords: Wood wastes; Activated carbon; Response surface methodology; Supercapacitor, $\mathrm{CO}_{2}$ capture

\footnotetext{
* Corresponding autor, Tel.: +34 985119090; Fax: +34 985297662;

E-mail address: teresa@incar.csic.es (T.A. Centeno)
} 


\section{Introduction}

The increasing volume of lignocellulosic wastes generated by diverse industrial activities is urging economically viable methodology for the reduction of their environmental impact. At present, they are primarily aimed at generating energy, either directly through combustion processes or indirectly, by preparing the so-called biofuels. However, the current needs for low-cost nanoporous carbons have led to growing research on the reassessing of lignocellulosic residues as precursors of activated carbons with uses in a large variety of fields $[1,2]$.

Activated carbons are a type of carbons that have been processed to make them extremely porous. Their structure consists of interconnected cavities between pseudographitic layers which results in a high internal surface area [1-3].

Lignocellulosic materials (wood sawdust, nutshells, fruit stones, rice husks, etc.) are widely used as precursors and, actually, account for around $45 \%$ of the total raw materials used for the manufacture of activated carbon. Two different methods are employed for the preparation of activated carbons with a wide variety of physicochemical properties $[3,4]$.

The so-called physical activation usually involves a two-step process: carbonization at $500-700^{\circ} \mathrm{C}$ followed by activation via the partial gasification of carbon at $800-1000^{\circ} \mathrm{C}$ in a stream of steam, air, carbon dioxide, etc. On the other hand, chemical activation consists in mixing the precursor with an activating reagent such as $\mathrm{H}_{3} \mathrm{PO}_{4}, \mathrm{ZnCl}_{2}, \mathrm{KOH}$, etc. and subsequent pyrolysis in the absence of air. Depending on the activating agent, the temperature usually ranges between 500 and $900^{\circ} \mathrm{C}[2,4,5]$. The resulting carbon is washed extensively to remove the chemical reagent.

Although the physical activation is the most widely used method, nowadays the chemical process is receiving more attention as it often involves only one heating step, 
achieved at much lower temperatures, and the carbon yield is higher. Besides, upon the chemical activation, the physico-chemical characteristics of the resulting carbon products can be easily tuned by adjusting the experimental conditions $[3,4]$. However, the profitability of the chemical activation is strongly dependent on the efficient recovery of the activating agent, either for reuse or for the by-products production.

Activated carbons are mostly used as industrial adsorbents for the purification of liquid and gas streams and for separating gas mixtures. On a smaller scale, they also act as catalyst supports and chromatographic columns. The current expansion of the applications of nanoporous carbons $[3,4,6-8]$ is driving the search for materials economically more competitive than those available on the market.

Recently, activated carbons have emerged as one of the most suitable materials for supercapacitors [6]. These devices correspond to a new type of reversible electrical energy storage systems which display high power-energy capability and long cycle life. These particular properties make them suitable for numerous applications such as power electronics, backup power systems, digital electronic devices, wind turbines, electric vehicles, etc. However, their widespread application has not been attained due to a high cost/performance ratio. Current research is contributing to lowered costs through the use of a large variety of biomass residues as raw materials of activated carbons with enhanced performance for supercapacitors.

In view of the significant contribution of $\mathrm{CO}_{2}$ emissions from the combustion of fossil fuels to the global climate change, their abatement is now a major challenge. Among a variety of technologies, a promising alternative is to use porous carbons as sorbents for capturing $\mathrm{CO}_{2}$ in power stations. Taking into account the potential production needs required by this application, the use of biomass renewable sources for 
fabricating these materials seems highly desirable [7,8]. Unfortunately, to date this approach has hardly been explored.

At present, industries involved in the processing of wood are urging research to upgrade the derivatives through the production of added-value materials with industrial applications. In this context, this work provides an insight into the potentiality of wastes generated in the chemical processing of birch wood such as substandard kraft cellulose and hydrolysis lignin (non-hydrolyzed solid residues from bioethanol production) and chips and bark derived from the mechanical processing of birch wood as low-cost precursors of nanoporous carbons.

The efficiency of the hydroxides of alkali metals as activating agents of lignocellulosic materials has been reported $[9,10]$. Here, we present a novel route based on a treatment with $\mathrm{NaOH}$. In the present case, the advantage of $\mathrm{NaOH}$ over others is the ability of being recovered through the SRK process, well-known in the pulp-andpaper industry.

The suitability of the resulting nanoporous carbons for electrodes in supercapacitors as well as for $\mathrm{CO}_{2}$ capture in power stations is illustrated by comparative evaluation.

\section{Materials and Methods}

\subsection{Materials}

Diverse wastes derived from birch-wood have been used as raw materials. They came from the chemical processing of wood such as substandard kraft cellulose and non-hydrolyzed solid residues from bioethanol production (hydrolysis lignin) and from the mechanical processing such as chips and bark.

The fraction with a particle size of 0.16-0.2 mm was selected for the study.

\subsection{Methods}




\subsubsection{Preparation of activated carbons}

Figure 1 illustrates schematically the novel method followed in the preparation of activated carbons. Briefly, the precursor was first heat treated under $\mathrm{N}_{2}$ at temperatures ranging between 375 and $550^{\circ} \mathrm{C}$ with a soaking time from 90 to $300 \mathrm{~min}$.

As previously reported by Kalinicheva et al. [5], such low-temperature pyrolysis of lignocellulosic materials notably decreases the oxygen content available to react with the activating agent and, therefore, its consumption is significantly reduced. On the other hand, pre-pyrolysis also generates a certain porosity which favours the subsequent impregnation with the chemical reagent, resulting in a more efficient activation [11].

The pyrolized material was mixed with 40 wt.\% aqueous solution of $\mathrm{NaOH}$. The mixing ratio, referred to the mass of the non-pyrolized raw material, was between 50 and 215 wt.\%. Such a mixture was subsequently carbonized at temperatures in the range $575-800^{\circ} \mathrm{C}$ with dwell times between 90 and 300 min. Finally, the activated carbons were washed with deionized water and $1 \%$ acetic acid solution until a $\mathrm{pH}$ of approximately 5 was obtained. The carbons were dried at $105^{\circ} \mathrm{C}$.

In some cases, the precursor was first impregnated with 2 and 4 wt.\% (referred to the o.d. precursor) of aqueous solution of $\mathrm{H}_{3} \mathrm{PO}_{4}(6 \mathrm{wt} . \%)$ and, subsequently, dried at $40^{\circ} \mathrm{C}$ under reduced pressure. This was followed by the procedure previously described (Figure 1).

Details of the experimental conditions used for the materials preparation are summarized in Table 1.

\subsubsection{Chemical analysis of carbons}

Wood wastes-based carbons are of high purity, with ash content in the range 0.2$0.4 \%$. The elemental analysis was performed with Elemental Analysensysteme GmbHvario MACRO CHNS. The oxygen content of carbons is reported in Table 1. 


\subsubsection{Textural characterization of carbons}

The solids have been characterized by $\mathrm{N}_{2}$ adsorption at $77 \mathrm{~K}$ (Micromeritics ASAP 2010). The analysis of $\mathrm{N}_{2}$ isotherms by the Dubinin-Radushkevich (DR) equation provided the micropore volume $\left(\mathrm{W}_{\mathrm{o}}\right)$ and the characteristic energy $\left(\mathrm{E}_{\mathrm{o}}\right)$ of the carbons. It has been shown that the latter is related to the average micropore width, $\mathrm{L}_{0}$, of the locally slit-shaped micropores by $\mathrm{L}_{\mathrm{o}}(\mathrm{nm})=10.8 /\left(\mathrm{E}_{\mathrm{o}}\left(\mathrm{kJ} \mathrm{mol}^{-1}\right)-11.4\right)[3]$. By assuming the model of locally slit-shaped micropores, the surface area of micropore walls was estimated by the geometrical relation $\mathrm{S}_{\mathrm{mi}}\left(\mathrm{m}^{2} \mathrm{~g}^{-1}\right)=2000 \mathrm{~W}_{\mathrm{o}}\left(\mathrm{cm}^{3} \mathrm{~g}^{-1}\right) / \mathrm{L}_{\mathrm{o}}(\mathrm{nm})$.

On the other hand, the classical comparison plot based on the $\mathrm{N}_{2}$ adsorption on a non-porous reference (Vulcan $3 G$ ) provided the total pore volume $\mathrm{V}_{\mathrm{p}}$ and the external surface area $\mathrm{S}_{\mathrm{e}}$ of the carbons [12]. The combination of both approaches led to the total surface area $\mathrm{S}_{\text {totalDR }}=\mathrm{S}_{\mathrm{mi}}+\mathrm{S}_{\mathrm{e}}$. As summarized in Table 2, $\mathrm{S}_{\text {totalDR }}$ is in good agreement with the total surface area obtained from the analysis of $\mathrm{N}_{2}$ isotherm by other methods such as the so-called SPE technique $\left(\mathrm{S}_{\text {comp }}\right)[12,13]$. These areas and their averages $\mathrm{S}_{\mathrm{av}}$ $=\left(\mathrm{S}_{\text {totalDR }}+\mathrm{S}_{\text {comp }}\right) / 2$ are listed in Table 2.

The pore size distributions (PSD) of the mesopores were obtained by applying the Kruk-Jaroniec-Sayari (KJS) method to the adsorption branch [14].

\subsubsection{Response surface methodology}

Response surface methodology (RSM) is a multivariate statistical technique used to optimize processes, i.e., to find the conditions at which to apply a procedure to obtain the best possible response within the experimental region studied [15].

In the present study, RSM was used to assess the effect of preliminary impregnation with $\mathrm{H}_{3} \mathrm{PO}_{4}$ of kraft cellulose wastes on the subsequent activation process. The independent variables were: the impregnating $\left[\mathrm{H}_{3} \mathrm{PO}_{4} /\right.$ cellulose $]$ and the activating $\left[\mathrm{NaOH} /\right.$ cellulose] ratios, respectively $\% \mathrm{H}_{3} \mathrm{PO}_{4}$ and $\% \mathrm{NaOH}$. The responses or 
dependent variables were the carbon yield, oxygen content and textural properties (total pore volume, $\mathrm{V}_{\mathrm{p}}$, micropore volume, $\mathrm{W}_{\mathrm{o}}$, average micropore width, $\mathrm{L}_{\mathrm{o}}$, micropore surface area, $\mathrm{S}_{\mathrm{mi}}$, and total surface area, $\mathrm{S}_{\mathrm{av}}$ ) of the resulting activated carbons. A threelevel full factorial design was chosen, which involved the 13 experiments shown in Table 3. All the experiments were executed in a random order.

The levels of the independent variables are coded in order to compare variables with different units or of different orders of magnitude, so they all will affect the response evenly. The codification consists of transforming each studied real value into coordinates inside a scale with dimensionless values, which must be proportional at its location in the experimental space. Table 3 shows the coded values of the independent variables (in parentheses) as well as the experimental values obtained for some of the response variables.

The mathematical-statistical approach consisted of the fit of a second-order polynomial function (eq. 4) with two independent variables, $x_{1}$ and $x_{2}$, to the experimental data set

$$
y=\beta_{0}+\beta_{1} x_{1}+\beta_{2} x_{2}+\beta_{12} x_{1} x_{2}+\beta_{11} x_{1} x_{1}+\beta_{22} x_{2} x_{2}+\varepsilon
$$

where $\beta_{0}$ is the constant term, $\beta_{1}$ and $\beta_{2}$ represent the coefficients of the lineal parameters, $\beta_{12}$ corresponds to the coefficient of the interaction parameter, $\beta_{11}$ and $\beta_{22}$ represent the coefficients of the quadratic parameters and $\varepsilon$ is the residual associated to the experiments. Multiple regression analysis based on the method of least squares, generated $\beta$ coefficients with the lowest residual $\varepsilon$.

The evaluation of the model's fitness was carried out applying analysis of variance (ANOVA) and lack-of-fit test. To establish whether a parameter is significant, 
a $p$-value test with a $95 \%$ level of confidence was applied to the experimental results. The model accuracy was checked by calculating the coefficient of determination adjusted by the number of variables $\left(\mathrm{Adj}-R^{2}\right)$ and the absolute average deviation (AAD). Adj- $R^{2}$ represents the proportion of variability of the data that is accounted for the model and it must be close to 1.0. The deviation between experimental and predicted values (AAD) must be as small as possible and was estimated by [16]

$$
\operatorname{AAD}(\%)=100 \times\left[\sum_{i=1}^{n}\left(\left|y_{i, \exp }-y_{i, \text { cal }}\right| / y_{i, \text { exp }}\right)\right] / n
$$

where $y_{i, \exp }$ and $y_{i, \mathrm{cal}}$ are the experimental and calculated responses, respectively, and $n$ the number of experiments.

The statistical analyses were carried out by the software SPSS Statistics 17.0. Response surface plots were generated by software SigmaPlot 8.0.

\subsubsection{Performance of carbons as electrodes in supercapacitors}

Two-electrode capacitors were assembled in a Swagelok ${ }^{\circledR}$ system with pellets of around $10 \mathrm{mg}$ in weight. The electrode was composed of $75 \mathrm{wt} \% \%$ of carbon, $20 \mathrm{wt} . \%$ of polyvinylidene fluoride and 5 wt.\% of carbon black. $2 \mathrm{M} \mathrm{H}_{2} \mathrm{SO}_{4}$ aqueous solution and $1 \mathrm{M}\left(\mathrm{C}_{2} \mathrm{H}_{5}\right)_{4} \mathrm{NBF}_{4}$ in acetonitrile were used as electrolytes. A glassy fibrous material played the role of separator. The electrochemical measurements involved galvanostatic charging-discharging cycles at current densities between 1 and $100 \mathrm{~mA} \mathrm{~cm}{ }^{-2}$ (potentiostat-galvanostat Autolab-Ecochimie PGSTAT 30). The cell voltage ranged from 0 to $0.8 \mathrm{~V}$ for the aqueous medium and between 0 and $2 \mathrm{~V}$ for the aprotic electrolyte.

\subsubsection{Performance of carbons as adsorbents for $\mathrm{CO}_{2}$ capture.}

$\mathrm{CO}_{2}$ capture capacity was experimentally evaluated from the maximum mass increase of the sample when exposed to a pure $\mathrm{CO}_{2}$ atmosphere at $298 \mathrm{~K}$ and 1 and 20 
bar (magnetic suspension balance (Rubotherm-VTI). It was reported in terms of mass of $\mathrm{CO}_{2}$ per mass of dry adsorbent, $\mathrm{g} \mathrm{CO}_{2} / 100 \mathrm{~g}$ carbon (wt \%).

\section{Results and Discussion}

\subsection{Porous characteristics of wood wastes-based carbons}

Table 2 illustrates that the chemical activation of the present birch wood-wastes with $\mathrm{NaOH}$ at temperatures in the range $575-800^{\circ} \mathrm{C}$ results in highly porous carbons. The analysis of the $\mathrm{N}_{2}$ isotherm reports that their porosity consists mainly of micropores with volumes $\mathrm{W}_{\mathrm{o}}$ between 0.24 and $1.15 \mathrm{~cm}^{3} \mathrm{~g}^{-1}$ and average widths $\mathrm{L}_{\mathrm{o}}$ above $1 \mathrm{~nm}$. The KJS-analysis shows some mesoporosity mostly constituted by pores smaller than 10 nm. Their contribution to the total area is limited and the outer surface generally accounts for less than $3 \%$ of the overall specific surface area (Table 2).

It is shown that the Dubinin's theory and the comparison plot lead to specific surface areas, respectively $\mathrm{S}_{\text {total }} \mathrm{DR}$ and $\mathrm{S}_{\text {comp }}$, which are in good agreement. Their average $S_{a v}$ is a reliable assessment of the total surface area and it ranges between 420 and $1469 \mathrm{~m}^{2} \mathrm{~g}^{-1}$. Although the traditional and still widespread use of BET-equation may be unreliable for microporous carbons and the BET-surface area is often in disagreement with $\mathrm{S}_{\mathrm{av}}$ [17], $\mathrm{S}_{\mathrm{BET}}$ is also included in Table 2 for comparison purposes.

As a high volume of micropores is one of the major advantages of activated carbons over other porous materials, this parameter can be taken as a reference for evaluating the potential of the precursors as well as the profitability of the activation procedure. Fig. 2 shows that the present activated carbons reach a porosity development which surpass that achieved with other methods and precursors quoted in the literature $(7,8,18-34)$. It is also noted that the micropore volume is based solely on the precursor nature, being relatively independent of the activation degree. 
It appears that the textural properties of kraft cellulose-derived materials (Table 2) are comparable to those reported for standard activated carbons, with total specific surface areas $S_{a v}$ virtually between 600 and $1000 \mathrm{~m}^{2} \mathrm{~g}^{-1}$ and pores of 1-1.4 $\mathrm{nm}$ [1-4]. On the other hand, hydrolysis lignin, chips and bark eventually lead to higher porosity development (Fig. 2), most carbons achieving specific surface areas well above 1100 $\mathrm{m}^{2} \mathrm{~g}^{-1}$ with pores centered in the supermicropores range $(1.3-1.7 \mathrm{~nm})$ (Table 2).

Figure 3 illustrates the significant influence of the precursor nature on the evolution of the microporosity itself (references in Table 4). It is observed that the process prepyrolysis $+\mathrm{NaOH}$ activation works efficiently with all our wastes but resulting carbons tend to cluster in families. As a consequence of the structural peculiarities and the composition of the raw material, they follow general trends that suggest certain limits for the porosity development. This provides an insight into the potential use of these precursors as raw materials of activated carbons.

\subsection{Effect of preliminary impregnation with $\mathrm{H}_{3} \mathrm{PO}_{4}$ on the activation process.}

Table 5 shows the results of the fit of the Eq. (1) to the experimental data by multiple regression analysis and those of the evaluation of the model's fitness by ANOVA, together with the Adj- $R^{2}$ and AAD values. Only the results corresponding to the carbon yield, the oxygen content, the average micropore width and the total surface area are included. Other textural parameters (total pore volume, micropore volume and micropore surface area) followed a pattern similar to that of total surface area (data not shown).

The ANOVA tests showed that the models for the carbon yield, total surface area and oxygen content were statistically significant at 95\% confidence level (model $p$ value $<0.05$ ), whereas their lack-of-fit was found statistically no significant at $95 \%$ confidence level ( $p$-value $>0.05$ ). However, the model corresponding to the average 
micropore width was no significant (model $p$-value $>0.05$ ), indicating that $\% \mathrm{H}_{3} \mathrm{PO}_{4}$ and $\% \mathrm{NaOH}$ had not a statistically significant influence on this variable.

Table 5 also indicates which of the terms of the models were statistically significant at $95 \%$ confidence level $(p$-value $<0.05)$. No-statistically significant $(p$ value $>0.05)$ parameters were eliminated from the models. The Adj- $R^{2}$ and the AAD values were acceptable: $0.749-0.853$ and $4.7-6.9 \%$, respectively.

The obtained models for the response variables as a function of the independent variables after eliminating the no-significant terms and decoding the coded coefficient values were the following:

Carbon yield $(\%)=19.043+3.574 \% \mathrm{H}_{3} \mathrm{PO}_{4}-0.509\left(\% \mathrm{H}_{3} \mathrm{PO}_{4}\right)^{2}$

Oxygen content $(\%)=11.725-3.214 \% \mathrm{H}_{3} \mathrm{PO}_{4}+0.040 \% \mathrm{NaOH}+0.481\left(\% \mathrm{H}_{3} \mathrm{PO}_{4}\right)^{2}(4)$

Total surface area, $\mathrm{S}_{\mathrm{av}}\left(\mathrm{m}^{2} \mathrm{~g}^{-1}\right)=439.679-50.167 \% \mathrm{H}_{3} \mathrm{PO}_{4}+7.007 \% \mathrm{NaOH}$

The response surface plots derived from Eqs. (3-5) display the impregnating $\left(\% \mathrm{H}_{3} \mathrm{PO}_{4}\right)$ and activating $(\% \mathrm{NaOH})$ ratios that, within the experimental region studied, optimize the yield, the oxygen content and the total surface area of the resulting activated carbons. As illustrated by Fig. 4a, the impregnation of cellulose wastes with $\mathrm{H}_{3} \mathrm{PO}_{4}$ prior to pyrolysis increases the yield of the activation process whereas it results in carbons with less oxygen content (Fig. 4b). According to previous reports, the impregnation of biomass with certain agents such as $\mathrm{H}_{3} \mathrm{PO}_{4}$ reduces the oxygen content and favours dehydration and condensation reactions during subsequent heat treatment. Both processes lead to less volatile matter release and, consequently, to higher carbon yield [11]. Figures 4a-b also indicate a rather limited effect of the amount of activating agent on the carbon yield and oxygen content. 
The evolution observed for the total surface area (Fig. 4c) shows that the porosity development depends linearly on both variables. Whereas $\mathrm{H}_{3} \mathrm{PO}_{4}$ pre-impregnation appears to hinder the porosity development, increasing amount of $\mathrm{NaOH}$ leads to much more porous materials.

Depending on the activating ratio, kraft-cellulose generates carbons with micropore volumes ranging between 0.46 and $0.77 \mathrm{~cm}^{3} \mathrm{~g}^{-1}$ (Table 2) whereas its effect on the average micropore size is not significant $\left(\mathrm{L}_{\mathrm{o}} \sim 1.4 \mathrm{~nm}\right)$. On the other hand, the precursor impregnated with $\mathrm{H}_{3} \mathrm{PO}_{4}$ follows the relationship $\Delta \mathrm{L}_{\mathrm{o}} / \Delta \mathrm{W}_{\mathrm{o}}=2.55 \mathrm{~nm} /\left(\mathrm{cm}^{3} \mathrm{~g}^{-}\right.$ 1) (Fig. 3) with $1100 \mathrm{~m}^{2} \mathrm{~g}^{-1}$ as upper limit for the specific surface area.

Figure 4 illustrates that the impregnation of wastes with $3.5 \%$ of $\mathrm{H}_{3} \mathrm{PO}_{4}$ leads to the highest carbon yield (25.3\%) whereas maximum specific surface area $\left(1140 \mathrm{~m}^{2} \mathrm{~g}^{-1}\right)$ is achieved by activating the non-impregnated wastes with $100 \%$ of $\mathrm{NaOH}$. As far as the process profitability plays a major role from an economical point of view, a compromise among both variables has to be found. It seems that pre-impregnation with $2 \% \mathrm{H}_{3} \mathrm{PO}_{4}$ and activation with a $100 \% \mathrm{NaOH}$ could be a good combination. In any case, the oxygen content in the resulting carbons should also be considered for their future applications.

\subsection{Applications of the activated carbons}

\subsubsection{Performance as electrodes in supercapacitors}

Activated carbons are currently most widely used as electrode material in supercapacitors. Their performance is based on the charging and discharging of the electrical double-layer formed by electrostatic interactions at the interface between the charged surface of a carbon electrode and the ions of a conducting electrolyte [6]. It has been shown that there also may be a contribution of pseudocapacitive effects from 
certain surface functional groups such as oxygen- and nitrogen-containing complexes $[6]$.

The textural and chemical characteristics suggest a potentiality for the use of carbons of Table 2 as capacitor electrodes. However, these expectations contrast with the rather poor performance displayed by the devices prepared with materials derived from kraftcellulose and hydrolysis lignin. Although they present specific capacitances above 100 $\mathrm{Fg}^{-1}$ in the aqueous electrolyte, these materials are not a good option for high power applications since the energy density drops with increasing power output.

The importance of electric conductivity of carbon electrodes, especially for achieving high power delivery, has been reflected in several studies based on carbons treated at $700-1000^{\circ} \mathrm{C}[6]$. Attempts to enhance the suitability of carbons of series $\mathrm{C}$ and L by increasing the structural order of the pseudo-graphitic layers had a limited effect on the capacitor performance. As an example, carbon C6-600*800, obtained by post-treatment at $800^{\circ} \mathrm{C}$ under $\mathrm{N}_{2}$ of $\mathrm{C}-6$ provides only $2 \mathrm{Wh} \mathrm{kg}^{-1}$ at $2590 \mathrm{~W} \mathrm{~kg}^{-1}$ for $2 \mathrm{~V}$ $\left(\mathrm{C}_{2} \mathrm{H}_{5}\right)_{4} \mathrm{NBF}_{4} / \mathrm{CH}_{3} \mathrm{CN}$ devices, whereas it achieves power density around $828 \mathrm{~W} \mathrm{~kg}^{-1}$ at $1 \mathrm{Wh} \mathrm{kg}^{-1}$ in the $0.8 \mathrm{~V}-\mathrm{H}_{2} \mathrm{SO}_{4}$ system.

On the contrary, the activated carbons derived from chips and bark show specific capacitances as high as $308 \mathrm{Fg}^{-1}$ in the $\mathrm{H}_{2} \mathrm{SO}_{4}$ electrolyte and $200 \mathrm{Fg}^{-1}$ in the organic medium $\left(\mathrm{C}_{2} \mathrm{H}_{5}\right)_{4} \mathrm{NBF}_{4} /$ acetonitrile (Table 6 ), surpassing the values found by typical activated carbons [6]. A comparative evaluation based on Ragone-type plots relating power-density to achievable energy-density has confirmed the potentiality of birch wood-based carbons to be used as electrodes. As illustrated by Figure 5 for aqueous and organic electrolytes, capacitors built with carbons obtained by $\mathrm{NaOH}$-activation of chips and bark at $650-700^{\circ} \mathrm{C}$ favourably compete with that made of the activated carbon SC10, commercialized by Arkema-Ceca for supercapacitors. 


\subsection{2. $\mathrm{CO}_{2}$ capture capacity}

It has been reported that, in view of the diversity of experimental conditions, the design of carbon materials with optimized $\mathrm{CO}_{2}$ capture performance in power stations should be conducted differently depending on their application in post- or precombustion processes [35]. Table 6 , where the $\mathrm{CO}_{2}$ uptake of some activated carbons (selected from Tables 1-2) at $298 \mathrm{~K}$ and 1 and 20 bar is summarized, illustrates the promising characteristics of wood wastes-derived carbons for application in both postand pre-combustion $\mathrm{CO}_{2}$ capture processes.

The results obtained at 1 bar and $298 \mathrm{~K}$ (post-combustion conditions) illustrate excellent performance of the present carbons as $\mathrm{CO}_{2}$ sorbents, achieving uptakes in the range 11.4-15.9 wt\%. An overall assessment of a wide variety of activated carbon materials and data quoted in the literature reported a $\mathrm{CO}_{2}$ uptake upper-bound around $10-11 \mathrm{wt} \%$ for standard activated carbons under post-combustion conditions [35]. Such high values indicate a great contribution of narrow micropores below $0.6-0.7 \mathrm{~nm}$ where the $\mathrm{CO}_{2}$ adsorption takes place at low pressure.

Interestingly, the wood-based carbons also exhibit high $\mathrm{CO}_{2}$ capture capacities under pre-combustion conditions (20 bar and $298 \mathrm{~K}$ ). As reported in Table 6 , the $\mathrm{CO}_{2}$ uptakes are close to the $60-70 \mathrm{wt} . \%$ estimated as maximum capacity for standard activated carbons under pre-combustion conditions [35]. Higher $\mathrm{CO}_{2}$ retention capacities can only be found for carbons with a high micropore volume coming from pores above $1.5 \mathrm{~nm}$. This is the case of carbon WB-7 which achieves a $\mathrm{CO}_{2}$ uptake of 90.7 wt. $\%$ due to a great presence of pores $\left(\mathrm{W}_{\mathrm{o}}=1.13 \mathrm{~cm}^{3} \mathrm{~g}^{-1}\right)$ centered in the supermicroporosity range $(1.74 \mathrm{~nm})$. 
It is believed that the porous features of the wood wastes-derived carbons can still be further improved to optimize their performance for $\mathrm{CO}_{2}$ capture in power stations.

\section{Conclusions}

It is shown that the use of wastes generated in the chemical- and mechanical- processing of birch wood as precursors of low-cost porous carbons is a profitable approach. The chemical activation with $\mathrm{NaOH}$ at $575-800^{\circ} \mathrm{C}$ of diverse residues, such as substandard kraft cellulose, non-hydrolyzed solid residues derived from bioethanol production (hydrolysis lignin), chips and bark, resulted in a large variety of highly nanoporous carbons with surface areas above $1100 \mathrm{~m}^{2} \mathrm{~g}^{-1}$ and pores centered in the supermicropores range.

Comparative evaluations reported the potentiality of wood wastes-based carbons as electrodes for supercapacitors and adsorbents for $\mathrm{CO}_{2}$ capture.

\section{Acknowledgements}

The research leading to these results has received funding support of the European Community's Service Framework Programme (FP7/2007-2011,203459), from the Latvian Budget (Grant 1546), and the Latvian National Programme VPP-2,2.4,1.1. 


\section{References}

[1] Ioannidou O, Zabaniotou A, 2007. Agricultural residues as precursors for activated carbon production-A review. Renew Sust Energ Rev 2007; 11: 1966-2005.

[2] Rodríguez-Reinoso F, 2002. Production and applications of activated carbons. In: Schüth F, Sing KSW, Weitkamp J, editors. Handbook of Porous Solids vol. 3, Darmstad: Wiley-VCH; 2002, p. 1766-827.

[3] Stoeckli F. Characterization of microporous carbons by adsorption and immersion techniques. In: Patrick J, editor. Porosity in carbons-characterization and applications, London: Arnold; 1995, p. 67-97.

[4] Marsh H, Rodríguez-Reinoso F. Activated carbon. Amsterdam: Elsevier; 2006, p. 243-65.

[5] Kalinicheva OA, Bogdanovich NI, Dobele GV. Pre-pyrolysis of wood raw material in the synthesis of active carbons with $\mathrm{NaOH}$. Forest Journal (Lesnoy Zhurnal) 2008; 2: $117-22$.

[6] Inagaki M, Konno H, Tanaike O, 2010. Carbon materials for electrochemical capacitors. J Power Sources 2010;195: 7880-903.

[7] Plaza MG, Pevida C, Arias B, Fermoso J, Casal, MD, Martín CF, Rubiera F, Pis JJ. Development of low-cost biomass-based adsorbents for postcombustion $\mathrm{CO}_{2}$ capture. Fuel 2009; 88: 2442-7.

[8] Plaza MG, Pevida C, Martín CF, Fermoso J, Pis JJ, Rubiera F. Developing almond shell derived activated carbons as $\mathrm{CO}_{2}$ adsorbents. Sep Pur Technol 2010; 71: 102-6.

[9] Tsyganova S, Korolkova I, Bondarenko G, Chesnokov N, Kuznetsov B.Synthesis of active carbons from birch wood modified by phosphoric acid and potassium hydroxide. Journal of Siberian Federal University. Chemistry v. 3, 2009; 2: 275-81.

[10] Torne-Fernández V, Mateo-Sanz JM, Montane D, Fierro V. Statistical Optimization of Synthesis of Highly Microporous Carbons by Chemical Activation of Kraft Lignin with NaOH, J Chem Eng Data 2009; 54: 2216-21.

[11] Dobele G, Telysheva G, Bogdanovich N, 2006. Thermochemical activation of lignin for obtaining effective sorbents. In: Loureiro JM, Kartel MT, editors. Combined and Hybrid Adsorbents: Fundamentals and Applications (NATO Security through Science Series C: Environmental Security), Dordrecht: Springer; 2006, p. 225-30.

[12] Setoyama N, Suzuki T, Kaneko K. Simulation study of the relationship between a high-resolution $\alpha$ s-plot and the pore size distribution for activated carbons. Carbon 1998; 36: 1459-67.

[13] Wang ZM, Kanoh H, Kaneko K, Lu GQ, Do D. Structural and surface property changes of macadamia nut-shell char upon activation and high temperature treatment. Carbon 2002; 40: 1231-9.

[14] Kruk M, Jaroniec M, Sayari A. Application of large pore MCM-41 molecular sieves to improve pore size analysis using nitrogen adsorption measurements. Langmuir 1997;13: 6267-73.

[15] Myers RH, Montgomery DH. Response Surface Methodology, USA: John Wiley \& Sons; 1995. 
[16] Baş D, Boyacı İH. Modeling and optimization I: Usability of response surface methodology. J Food Eng 2007; 78: 836-45.

[17] Centeno TA, Stoeckli F. The assessment of surface areas in porous carbons by two model-independent techniques, the DR equation and DFT. Carbon 2010; 48: 2478-86.

[18] Carrott PJM, Ribeiro-Carrott MML, Mourão PAM. Pore size control in activated carbons obtained by pyrolysis under different conditions of chemically impregnated cork. J Anal Appl Pyrol 2006; 75: 120-7.

[19] El-Hendawy AA, Samra SE, Girgis BS. Adsorption characteristics of activated carbons obtained from corncobs. Colloid Surface A 2001;180: 209-21.

[20] Fernández E, Centeno TA, Stoeckli F, 2001. Chars and activated carbons prepared from asturian apple pulp. Adsorpt Sci Technol 2001; 19: 645-53.

[21] Girgis BS, Yunis SS, Soliman AM. Characteristics of activated carbon from peanut hulls in relation to conditions of preparation. Mater Lett 2002; 57: 164-72.

[22] Lillo-Ródenas MA, Lozano-Castelló D, Cazorla-Amorós D, Linares-Solano A. Preparation of activated carbons from Spanish anthracite II. Activation by $\mathrm{NaOH}$. Carbon 2001; 39: 751-9.

[23] Lillo-Ródenas MA, Marco-Lozar JP, Cazorla-Amorós D, Linares-Solano A. Activated carbons prepared by pyrolysis of mixtures of carbon precursor/alkaline hydroxide. J Anal Appl Pyrol 2007; 80: 166-74.

[24] Mui ELK, Ko DCK, McKay G. Production of active carbons from waste tyres - a review. Carbon 2004; 42: 2789-805.

[25] Savova D, Apak E, Ekinci E, Yardim F, Petrova N, Budinova T, Razvigorova M, Minkova V, 2001. Biomass conversion to carbon adsorbents and gas. Biomass Bioenerg 2001; 21: 133-42.

[26] Suárez-García F, Martínez-Alonso A, Tascón JMD. Pyrolysis of apple pulp: chemical activation with phosphoric acid. J Anal App Pyrol 2002; 63: 283-301.

[27] Olivares-Marín M, Fernández-González C, Macías-García A, Gómez-Serrano V. Preparation of activated carbons from cherry stones by activation with potassium hydroxide. Appl Surf Sci 2006; 252; 5980-3.

[28] Olivares-Marín M, Fernández-González C, Macías-García A, Gómez-Serrano V. Preparation of activated carbon from cherry stones by chemical activation with $\mathrm{ZnCl}_{2}$. Appl Surf Sci 2006; 252: 5967-71.

[29] Olivares-Marín M, Fernández-González C, Macías-García A, Gómez-Serrano V. Porous structure of activated carbon prepared from cherry stones by chemical activation with phosphoric acid. Energ Fuel 2007; 21: 2942-9.

[30] Ould-Idriss A, Stitou M, Cuerda-Correa EM, Fernández-González C, MacíasGarcía A, Alexandre Franco MF, Gómez-Serrano V. Preparation of activated carbons from olive-tree wood revisited. I. Chemical activation with $\mathrm{H}_{3} \mathrm{PO}_{4}$. Fuel Proc Technol 2011; 92: 266-70.

[31] Puziy AM, Poddubnaya OI, Martínez-Alonso A, Suárez-García F, Tascón JMD. Surface chemistry of phosphorus-containing carbons of lignocellulosic origin. Carbon 2005; 43: 2857-68. 
[32] Tsai WT, Chang CY, Lee SL. A low cost adsorbent from agricultural waste corn cob by zinc chloride activation. Bioresource Technol 1998; 64: 211-7.

[33] Wu FC, Tseng RL, Juang RS. Preparation of highly microporous carbons from fir wood by $\mathrm{KOH}$ activation for adsorption of dyes and phenols from water. Sep Purif Technol 2005; 47: 10-9.

[34] Zuo S, Yang J, Liu J. Effects of the heating history of impregnated lignocellulosic material on pore development during phosphoric acid activation. Carbon 2010; 48: 3293-311.

[35] Martín CF, Plaza MG, Pis JJ, Rubiera F, Pevida C, Centeno TA. On the limits of $\mathrm{CO}_{2}$ capture capacity of carbons. Sep Purif Technol 2010; 74: 225-9. 


\section{Figure Captions}

Figure 1. Schematic representation of the preparation of the activated carbons.

Figure 2. Micropore volume vs. carbon yield for the activation of different precursors under diverse conditions (references in Table 4).

Figure 3. Variation of the average micropore width $\mathrm{L}_{\mathrm{o}}$ with the micropore volume $\mathrm{W}_{\mathrm{o}}$ for carbons obtained by the activation of different precursors under diverse conditions (references in Table 4).

Figure 4. Response surface of predicted carbon yield (a), oxygen content (b) and total surface area (c) as a function of the impregnating $\left(\% \mathrm{H}_{3} \mathrm{PO}_{4}\right)$ and activating $(\% \mathrm{NaOH})$ ratios.

Figure 5. Energy storage vs. power release of capacitors with birch wood-based carbons as electrodes in aqueous $\left(\mathrm{H}_{2} \mathrm{SO}_{4}\right)$ and organic $\left(\left(\mathrm{C}_{2} \mathrm{H}_{5}\right)_{4} \mathrm{NBF}_{4} / \mathrm{ACN}\right)$ electrolytes:

From chips: WB-7 (०), WB-18 $(\square)$ and bark: BK-10 $(\Delta)$, BP-23 $(\diamond)$.

Commercial activated carbon SC-10 ( $\mathbf{a})$ is included for comparison.

The data corresponds to unit mass of carbon in the capacitor. 
Table 1. Preparation conditions and yield and oxygen content of the resulting carbons.

\begin{tabular}{|c|c|c|c|c|c|c|c|}
\hline Precursor & $\begin{array}{l}\text { Activated } \\
\text { carbon }\end{array}$ & $\begin{array}{c}\mathrm{H}_{3} \mathrm{PO}_{4} \\
(\%)\end{array}$ & $\begin{array}{c}\text { Pre-pyrolysis } \\
\left({ }^{\circ} \mathrm{C}, \mathrm{min}\right)\end{array}$ & $\begin{array}{c}\mathrm{NaOH} \\
(\%)\end{array}$ & $\begin{array}{c}\text { Activation } \\
\left({ }^{\circ} \mathrm{C}, \text { min }\right)\end{array}$ & $\begin{array}{l}\text { Yield } \\
(\%)\end{array}$ & $\begin{array}{c}\mathrm{O} \\
\text { (wt.\%) }\end{array}$ \\
\hline \multirow{20}{*}{$\begin{array}{c}\text { Kraft } \\
\text { cellulose }\end{array}$} & $\mathrm{C}-1$ & 0 & 400,180 & 50 & 600,90 & 20.6 & 13.1 \\
\hline & $\mathrm{C}-2$ & 0 & 400,180 & 60 & 600,90 & 16.4 & 9.0 \\
\hline & $\mathrm{C}-3$ & 0 & 400,180 & 70 & 600,90 & 21.8 & 12.0 \\
\hline & C-4 & 0 & 400,180 & 80 & 600,90 & 17.5 & 16.0 \\
\hline & $\mathrm{C}-5$ & 0 & 400,180 & 100 & 600,90 & 16.8 & 17.0 \\
\hline & C-6 & 2 & 400,180 & 50 & 600,90 & 23.9 & 9.3 \\
\hline & C-6-650 & 2 & 400,180 & 50 & 650,90 & 24.3 & 7.0 \\
\hline & C-6-700 & 2 & 400,180 & 50 & 700,90 & 23.7 & 8.5 \\
\hline & C-6-750 & 2 & 400,180 & 50 & 750,90 & 25.9 & 6.3 \\
\hline & C-6-800 & 2 & 400,180 & 50 & 800,90 & 22.1 & 8.3 \\
\hline & C-6-600-800 & 2 & 400,180 & 50 & 800,90 & 27.2 & 5.9 \\
\hline & C-7 & 2 & 400,180 & 60 & 600,90 & 24.2 & 8.9 \\
\hline & C-8 & 2 & 400,180 & 70 & 600,90 & 26.7 & 9.5 \\
\hline & C-9 & 2 & 400,180 & 80 & 600,90 & 23.0 & 10.4 \\
\hline & $\mathrm{C}-10$ & 2 & 400,180 & 100 & 600,90 & 22.4 & 9.7 \\
\hline & $\mathrm{C}-11$ & 4 & 400,180 & 50 & 600,90 & 25.8 & 8.5 \\
\hline & $\mathrm{C}-12$ & 4 & 400,180 & 60 & 600,90 & 24.7 & 9.4 \\
\hline & $\mathrm{C}-13$ & 4 & 400,180 & 70 & 600,90 & 24.3 & 9.4 \\
\hline & C-14 & 4 & 400,180 & 80 & 600,90 & 24.0 & 10.0 \\
\hline & $C-15$ & 4 & 400,180 & 100 & 600,90 & 25.5 & 10.4 \\
\hline \multirow{3}{*}{$\begin{array}{c}\text { Hydrolysis } \\
\text { lignin }\end{array}$} & LN-1 & 0 & 400,90 & 100 & 700,90 & 38.5 & 13.8 \\
\hline & LN-2 & 0 & 550,90 & 200 & 700,90 & 36.7 & 11.5 \\
\hline & LN-2.5 & 0 & 550,90 & 250 & 700,90 & 35.9 & - \\
\hline \multirow{10}{*}{$\begin{array}{l}\text { Birch wood } \\
\text { chips }\end{array}$} & WB-6 & 6 & 525,300 & 215 & 575,90 & 21.9 & 9.8 \\
\hline & WB-6x & 6 & 525,180 & 215 & 575,90 & 22.7 & 8.3 \\
\hline & WB-7 & 6 & 375,300 & 215 & 725,90 & 22.8 & 5.1 \\
\hline & WB-17 & 6 & 450,300 & 165 & 650,90 & 29.1 & 9.2 \\
\hline & WB-18 & 6 & 450,180 & 165 & 650,90 & 22.2 & 11.2 \\
\hline & WB-20 & 6 & 450,300 & 165 & 650,90 & 28.5 & 13.9 \\
\hline & WD-31 & 3 & 400,180 & 100 & 700,90 & 36.3 & 10.8 \\
\hline & WD-32 & 3 & 400,180 & 100 & 650,90 & 36.0 & 9.1 \\
\hline & WL-08 & 0 & 400,180 & 100 & 650,60 & 14.0 & 11.3 \\
\hline & WL-09 & 0 & 400,180 & 100 & 700,60 & 12.4 & 9.3 \\
\hline \multirow{5}{*}{$\begin{array}{l}\text { Birch wood } \\
\text { bark }\end{array}$} & BK-05 & 0 & 400,180 & 100 & 600,60 & 24.6 & 20.2 \\
\hline & BK-10 & 0 & 400,180 & 100 & 750,60 & 20.5 & 8.5 \\
\hline & BK-11 & 0 & 400,150 & 100 & 600,60 & 21.7 & 16.2 \\
\hline & BP-15 & 0 & 400,125 & 100 & 675,70 & 18.7 & 11.8 \\
\hline & BP-23 & 0 & 400,160 & 100 & 720,90 & 17.5 & 7.0 \\
\hline
\end{tabular}


Table 2. Textural characteristics of the activated carbons

\begin{tabular}{|c|c|c|c|c|c|c|c|c|c|c|}
\hline Precursor & Carbon & $\begin{array}{c}\mathrm{V}_{\mathrm{p}} \\
\left(\mathrm{cm}^{3} \mathrm{~g}^{-1}\right)\end{array}$ & $\begin{array}{c}\mathrm{W}_{\mathrm{o}} \\
\left(\mathrm{cm}^{3} \mathrm{~g}^{-1}\right)\end{array}$ & $\begin{array}{c}\mathrm{L}_{\mathrm{o}} \\
(\mathrm{nm})\end{array}$ & $\begin{array}{c}\mathrm{S}_{\mathrm{mi}} \\
\left(\mathrm{m}^{2} \mathrm{~g}^{-1}\right)\end{array}$ & $\begin{array}{c}\mathrm{S}_{\mathrm{e}} \\
\left(\mathrm{m}^{2} \mathrm{~g}^{-1}\right)\end{array}$ & $\begin{array}{l}\mathrm{S}_{\text {totalDR }}{ }^{(1)} \\
\left(\mathrm{m}^{2} \mathrm{~g}^{-1}\right)\end{array}$ & $\begin{array}{c}\mathrm{S}_{\text {comp }} \\
\left(\mathrm{m}^{2} \mathrm{~g}^{-1}\right)\end{array}$ & $\begin{array}{c}\mathrm{S}_{\mathrm{av}}^{(2)} \\
\left(\mathrm{m}^{2} \mathrm{~g}^{-1}\right)\end{array}$ & $\begin{array}{c}\mathrm{S}_{\mathrm{BET}} \\
\left(\mathrm{m}^{2} \mathrm{~g}^{-1}\right)\end{array}$ \\
\hline \multirow{20}{*}{$\begin{array}{c}\text { Kraft } \\
\text { cellulose }\end{array}$} & $\mathrm{C}-1$ & 0.49 & 0.46 & 1.37 & 672 & 7 & 679 & 685 & 682 & 1145 \\
\hline & C-2 & 0.68 & 0.59 & 1.35 & 874 & 4 & 878 & 845 & 862 & 1554 \\
\hline & $\mathrm{C}-3$ & 0.77 & 0.73 & 1.36 & 1074 & 7 & 1081 & 1054 & 1068 & 1782 \\
\hline & C-4 & 0.82 & 0.75 & 1.38 & 1083 & 8 & 1091 & 1124 & 1108 & 1913 \\
\hline & C-5 & 0.89 & 0.77 & 1.51 & 1020 & 11 & 1031 & 1014 & 1023 & 2032 \\
\hline & C-6 & 0.41 & 0.40 & 1.21 & 661 & 6 & 667 & 677 & 672 & 976 \\
\hline & C-6-650 & 0.28 & 0.26 & 1.00 & 520 & 6 & 526 & 515 & 521 & 410 \\
\hline & C-6-700 & 0.24 & 0.24 & 1.09 & 433 & 4 & 437 & 402 & 420 & 402 \\
\hline & C-6-750 & 0.33 & 0.31 & 1.06 & 585 & 6 & 593 & 641 & 541 & 586 \\
\hline & C-6-800 & 0.42 & 0.41 & 1.10 & 752 & 6 & 758 & 722 & 740 & 704 \\
\hline & C- $6-600 * 800$ & 0.39 & 0.35 & 0.98 & 724 & 4 & 728 & 695 & 712 & 566 \\
\hline & C-7 & 0.49 & 0.46 & 1.24 & 750 & 6 & 756 & 775 & 766 & 1197 \\
\hline & $\mathrm{C}-8$ & 0.57 & 0.52 & 1.32 & 791 & 7 & 798 & 757 & 778 & 1323 \\
\hline & C-9 & 0.72 & 0.64 & 1.35 & 948 & 6 & 954 & 987 & 971 & 1651 \\
\hline & $\mathrm{C}-10$ & 0.84 & 0.74 & 1.35 & 1096 & 5 & 1101 & 1109 & 1105 & 1758 \\
\hline & C-11 & 0.42 & 0.37 & 1.28 & 572 & 7 & 579 & 611 & 595 & 961 \\
\hline & C-12 & 0.63 & 0.51 & 1.29 & 786 & 17 & 803 & 790 & 797 & 1277 \\
\hline & C-13 & 0.56 & 0.52 & 1.39 & 748 & 7 & 756 & 768 & 762 & 1299 \\
\hline & C-14 & 0.54 & 0.50 & 1.50 & 667 & 7 & 674 & 652 & 663 & 1259 \\
\hline & $\mathrm{C}-15$ & 0.73 & 0.65 & 1.49 & 879 & 5 & 884 & 881 & 883 & 1728 \\
\hline Hydrolysis & LN-1 & 1.25 & 0.79 & 1.40 & 1129 & 33 & 1162 & 1186 & 1174 & 2128 \\
\hline \multirow{2}{*}{ lignin } & LN-2 & 0.69 & 0.60 & 0.99 & 1212 & 8 & 1220 & 1189 & 1205 & 1522 \\
\hline & LN-2.5 & 0.83 & 0.74 & 1.11 & 1334 & 9 & 1343 & 1345 & 1344 & 1890 \\
\hline \multirow{10}{*}{$\begin{array}{l}\text { Birch wood } \\
\text { chips }\end{array}$} & WB-6 & 0.98 & 0.84 & 1.48 & 1135 & 7 & 1142 & 1195 & 1169 & 2164 \\
\hline & WB-6x & 0.75 & 0.70 & 1.45 & 966 & 8 & 974 & 969 & 972 & 1709 \\
\hline & WB-7 & 1.69 & 1.13 & 1.74 & 1299 & 9 & 1308 & 1330 & 1319 & 3358 \\
\hline & WB-17 & 0.92 & 0.84 & 1.22 & 1377 & 4 & 1381 & 1353 & 1367 & 2119 \\
\hline & WB-18 & 1.50 & 1.15 & 1.59 & 1447 & 9 & 1456 & 1482 & 1469 & 3136 \\
\hline & WB-20 & 1.12 & 0.83 & 1.32 & 1258 & 17 & 1275 & 1211 & 1243 & 2174 \\
\hline & WD-31 & 0.95 & 0.82 & 1.26 & 1302 & 10 & 1312 & 1294 & 1303 & 2128 \\
\hline & WD-32 & 1.09 & 0.89 & 1.23 & 1447 & 18 & 1465 & 1471 & 1468 & 2366 \\
\hline & WL-08 & 1.17 & 0.84 & 1.31 & 1282 & 18 & 1300 & 1279 & 1290 & 2270 \\
\hline & WL-09 & 1.07 & 0.85 & 1.44 & 1180 & 12 & 1192 & 1181 & 1187 & 2210 \\
\hline \multirow{5}{*}{$\begin{array}{c}\text { Birch wood } \\
\text { bark }\end{array}$} & BK-05 & 0.80 & 0.72 & 1.18 & 1220 & 12 & 1232 & 1229 & 1231 & 1865 \\
\hline & BK-10 & 1.07 & 0.80 & 1.28 & 1250 & 18 & 1268 & 1229 & 1249 & 2192 \\
\hline & BK-11 & 0.84 & 0.71 & 1.30 & 1092 & 13 & 1105 & 1079 & 1092 & 1839 \\
\hline & BP-15 & 1.00 & 0.82 & 1.23 & 1333 & 15 & 1348 & 1359 & 1354 & 2130 \\
\hline & BP-23 & 1.35 & 1.00 & 1.52 & 1316 & 21 & 1337 & 1306 & 1322 & 2596 \\
\hline
\end{tabular}


Table 3. Independent variables and experimental values of the response variables for three-level full factorial design

\begin{tabular}{lccccccc}
\hline \multirow{2}{*}{ Run } & \multicolumn{2}{c}{ Independent variables } & & \multicolumn{4}{c}{ Response variables } \\
\cline { 2 - 3 } \cline { 5 - 7 } & $\% \mathrm{H}_{3} \mathrm{PO}_{4}$ & $\% \mathrm{NaOH}$ & & $\begin{array}{c}\text { Carbon yield } \\
(\%)\end{array}$ & $\begin{array}{c}\mathrm{L}_{\mathrm{o}} \\
(\mathrm{nm})\end{array}$ & $\begin{array}{c}\mathrm{S}_{\mathrm{av}} \\
\left(\mathrm{m}^{2} \mathrm{~g}^{-1}\right)\end{array}$ & $\begin{array}{c}\mathrm{O} \\
(\text { wt. } \%)\end{array}$ \\
\hline 1 & $0(-1)$ & $50(-1)$ & & 20.57 & 1.37 & 682 & 13.1 \\
2 & $0(-1)$ & $75(0)$ & & 19.75 & 1.37 & 1088 & 14.0 \\
3 & $0(-1)$ & $100(+1)$ & & 16.81 & 1.51 & 1023 & 17.0 \\
4 & $2(0)$ & $50(-1)$ & & 22.97 & 1.12 & 683 & 9.5 \\
5 & $2(0)$ & $75(0)$ & & 24.87 & 1.31 & 883 & 9.9 \\
6 & $2(0)$ & $100(+1)$ & & 22.39 & 1.35 & 1105 & 9.7 \\
7 & $4(+1)$ & $50(-1)$ & & 25.79 & 1.28 & 595 & 8.5 \\
8 & $4(+1)$ & $75(0)$ & & 24.16 & 1.45 & 713 & 9.7 \\
9 & $4(+1)$ & $100(+1)$ & & 25.64 & 1.49 & 883 & 10.4 \\
10 & $2(0)$ & $50(0)$ & & 25.86 & 1.40 & 953 & 10.5 \\
11 & $2(0)$ & $50(0)$ & & 23.87 & 1.21 & 813 & 9.7 \\
12 & $2(0)$ & $50(0)$ & & 23.00 & 1.13 & 927 & 10.9 \\
13 & $2(0)$ & $50(0)$ & & 26.13 & 1.42 & 895 & 11.0 \\
\hline
\end{tabular}


Table 4. Survey of carbons of Figures 2 and 3

\begin{tabular}{|c|c|c|c|}
\hline Symbol & Raw material & Activating agent & Ref. \\
\hline$\bullet$ & Kraft cellulose & $\mathrm{NaOH}$ & This work \\
\hline $\boldsymbol{\Delta}$ & Hydrolysis lignin & $\mathrm{NaOH}$ & This work \\
\hline घ & Birch wood chips & $\mathrm{NaOH}$ & This work \\
\hline 口. & Birch wood bark & $\mathrm{NaOH}$ & This work \\
\hline$\square$ & Olive tree wood & $\mathrm{H}_{3} \mathrm{PO}_{4}$ & [30] \\
\hline$\checkmark$ & Fir wood & $\mathrm{KOH}$ & [33] \\
\hline$\circ$ & Fir wood & $\mathrm{H}_{3} \mathrm{PO}_{4}$ & [34] \\
\hline$\square$ & Cork & $\begin{array}{c}\mathrm{KOH}, \mathrm{Na}_{2} \mathrm{CO}_{3}, \mathrm{~K}_{2} \mathrm{CO}_{3}, \\
\mathrm{H}_{3} \mathrm{PO}_{4}\end{array}$ & [18] \\
\hline+ & Soft wood & Not detailed & [20] \\
\hline$*$ & $\begin{array}{l}\text { Eucalyptus wood, Almond shell, } \\
\text { Coconut shell }\end{array}$ & $\mathrm{NaOH}$ & {$[22,23]$} \\
\hline$\Delta$ & $\begin{array}{l}\text { Apricot stones, cherry stones, grape } \\
\text { seeds, nut shells, almond shells }\end{array}$ & Steam & {$[25]$} \\
\hline - & Peanut hulls & \begin{tabular}{|c|} 
Steam, $\mathrm{ZnCl}_{2}, \mathrm{H}_{3} \mathrm{PO}_{4}$, \\
$\mathrm{KOH}$
\end{tabular} & [21] \\
\hline$\square$ & Corncob & $\mathrm{ZnCl}_{2}, \mathrm{H}_{3} \mathrm{PO}_{4}$, Steam & {$[19,32]$} \\
\hline$\circ$ & Cherry stones & $\mathrm{ZnCl}_{2}, \mathrm{H}_{3} \mathrm{PO}_{4}, \mathrm{KOH}$ & [27-29] \\
\hline$\Delta$ & Plum stone & Not detailed & [20] \\
\hline$\circ$ & Olive stones & Not detailed & [20] \\
\hline$\diamond$ & Olive stones & $\mathrm{CO}_{2}$ & [7] \\
\hline$\Delta$ & Almond shells & $\mathrm{CO}_{2}$ & {$[8]$} \\
\hline$\square$ & Apricot-peach stones & $\mathrm{H}_{3} \mathrm{PO}_{4}$ & [31] \\
\hline 0 & Apple pulp & $\mathrm{H}_{3} \mathrm{PO}_{4}$ & [26] \\
\hline$\diamond$ & Apple pulp & Steam, $\mathrm{CO}_{2}$ & Unpublished data \\
\hline$\square$ & Peat & Not detailed & [20] \\
\hline 田 & Anthracite & $\mathrm{NaOH}$ & [22] \\
\hline$*$ & Coals & $\mathrm{NaOH}$ & [23] \\
\hline - & Waste tyres & Steam, $\mathrm{CO}_{2}, \mathrm{KOH}$ & [24] \\
\hline
\end{tabular}


Table 5. Results of multiple regression analysis and ANOVA for the fit of the polynomial model to the carbon yield, average micropore width, total surface area and oxygen content experimental data

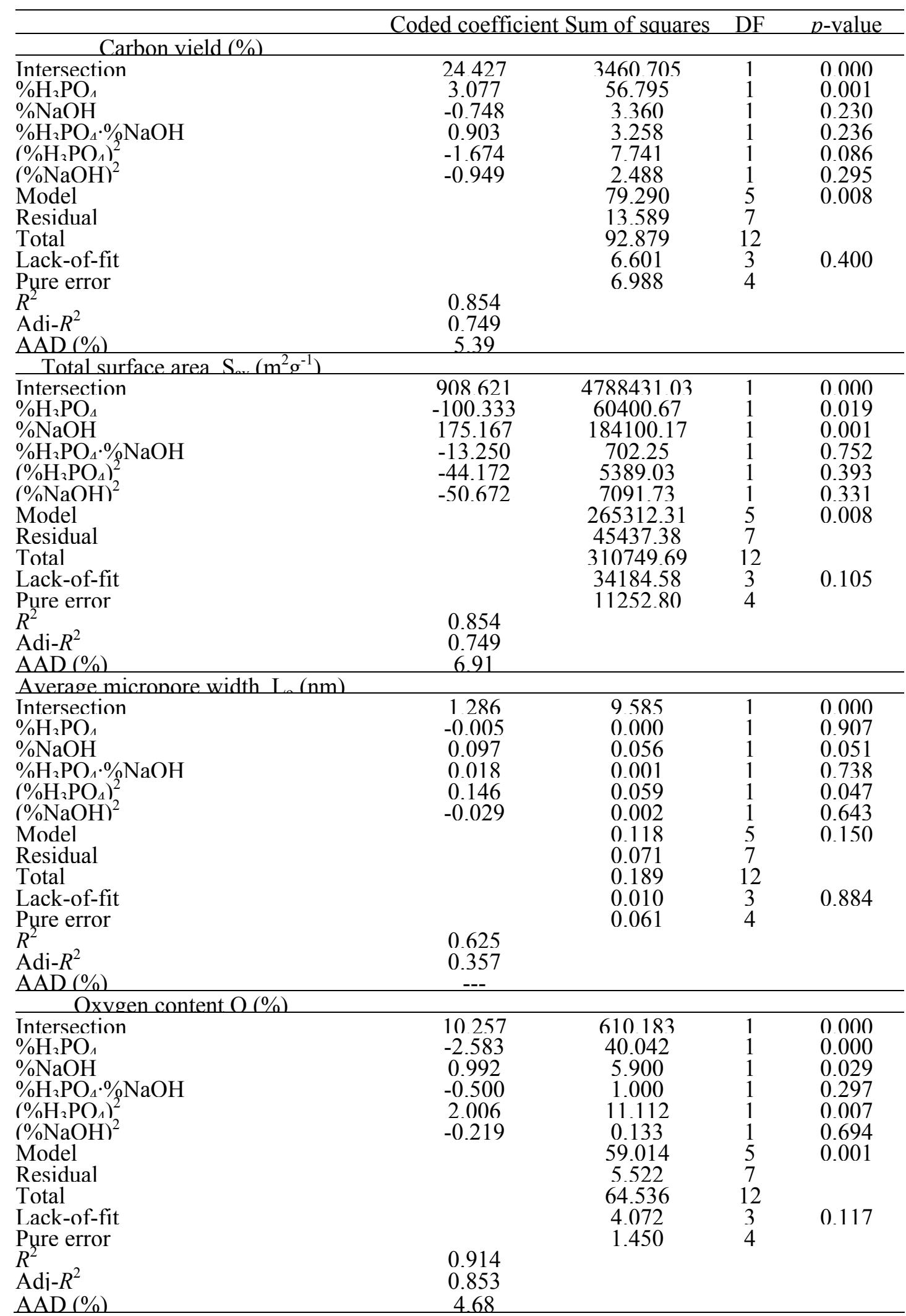


Table 6. Specific capacitance at $1 \mathrm{~mA} \mathrm{~cm}^{-2}$ and $\mathrm{CO}_{2}$ capture capacities at $298 \mathrm{~K}$ of some activated carbons selected from Tables 1-2

\begin{tabular}{|c|c|c|}
\hline \multirow{2}{*}{ Carbon } & \multicolumn{2}{|c|}{ Specific capacitance $\left(\mathrm{Fg}^{-1}\right)$ at $1 \mathrm{~mA} \mathrm{~cm}^{-2}$} \\
\hline & $2 \mathrm{M} \mathrm{H}_{2} \mathrm{SO}_{4}$ & $1 \mathrm{M}\left(\mathrm{C}_{2} \mathrm{H}_{5}\right)_{4} \mathrm{NBF}_{4} / \mathrm{AN}$ \\
\hline C-6 & 185 & 56 \\
\hline C-6-700 & 116 & 38 \\
\hline C-6-750 & 109 & 50 \\
\hline C-6-800 & 197 & 74 \\
\hline $\mathrm{C}-10$ & 279 & 106 \\
\hline $\mathrm{C}-11$ & 187 & 44 \\
\hline C- $6-600 * 800$ & 111 & 49 \\
\hline WB-7 & 258 & 200 \\
\hline WB-18 & 275 & 173 \\
\hline BP-23 & 308 & 164 \\
\hline BK-10 & 211 & 166 \\
\hline SC-10 & 165 & 100 \\
\hline \multirow{2}{*}{ Carbon } & \multicolumn{2}{|c|}{$\mathrm{CO}_{2}$ uptake (wt.\%) } \\
\hline & $1 \mathrm{bar}$ & 20 bar \\
\hline $\mathrm{C}-5$ & 13.3 & 65.3 \\
\hline $\mathrm{C}-10$ & 14.1 & 54.3 \\
\hline $\mathrm{C}-15$ & 13.1 & 55.4 \\
\hline WB-6 & 13.2 & 49.0 \\
\hline WB-7 & 11.4 & 90.7 \\
\hline WB-17 & 15.9 & 71.0 \\
\hline WB-18 & 12.3 & 73.1 \\
\hline WB-20 & 15.5 & 63.0 \\
\hline
\end{tabular}


Figure 1.

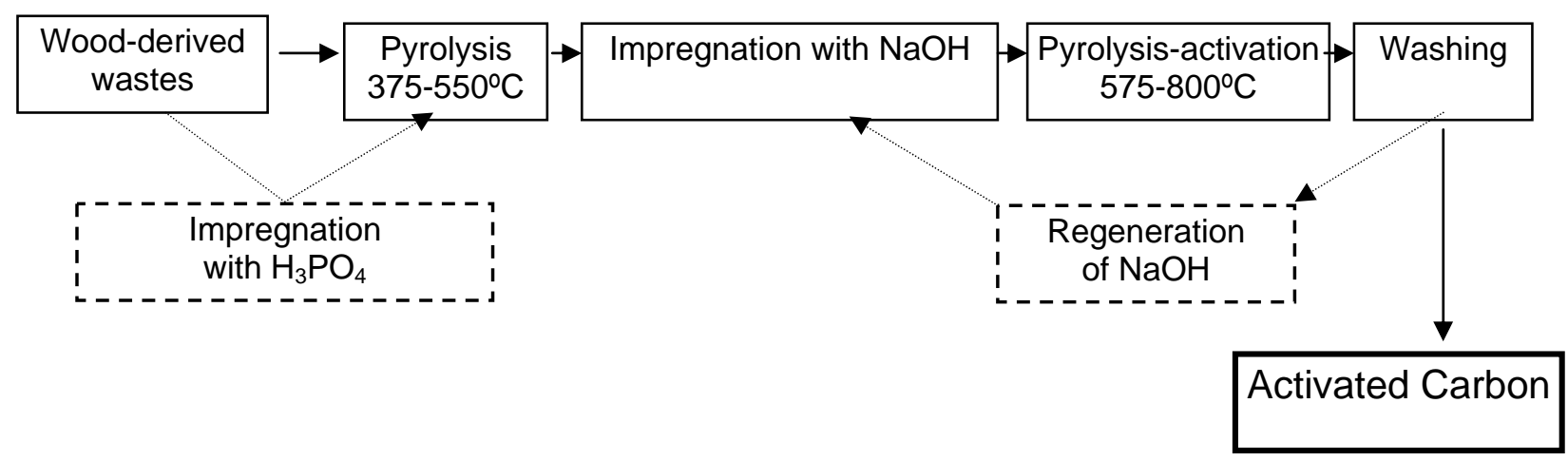


Figure 2.

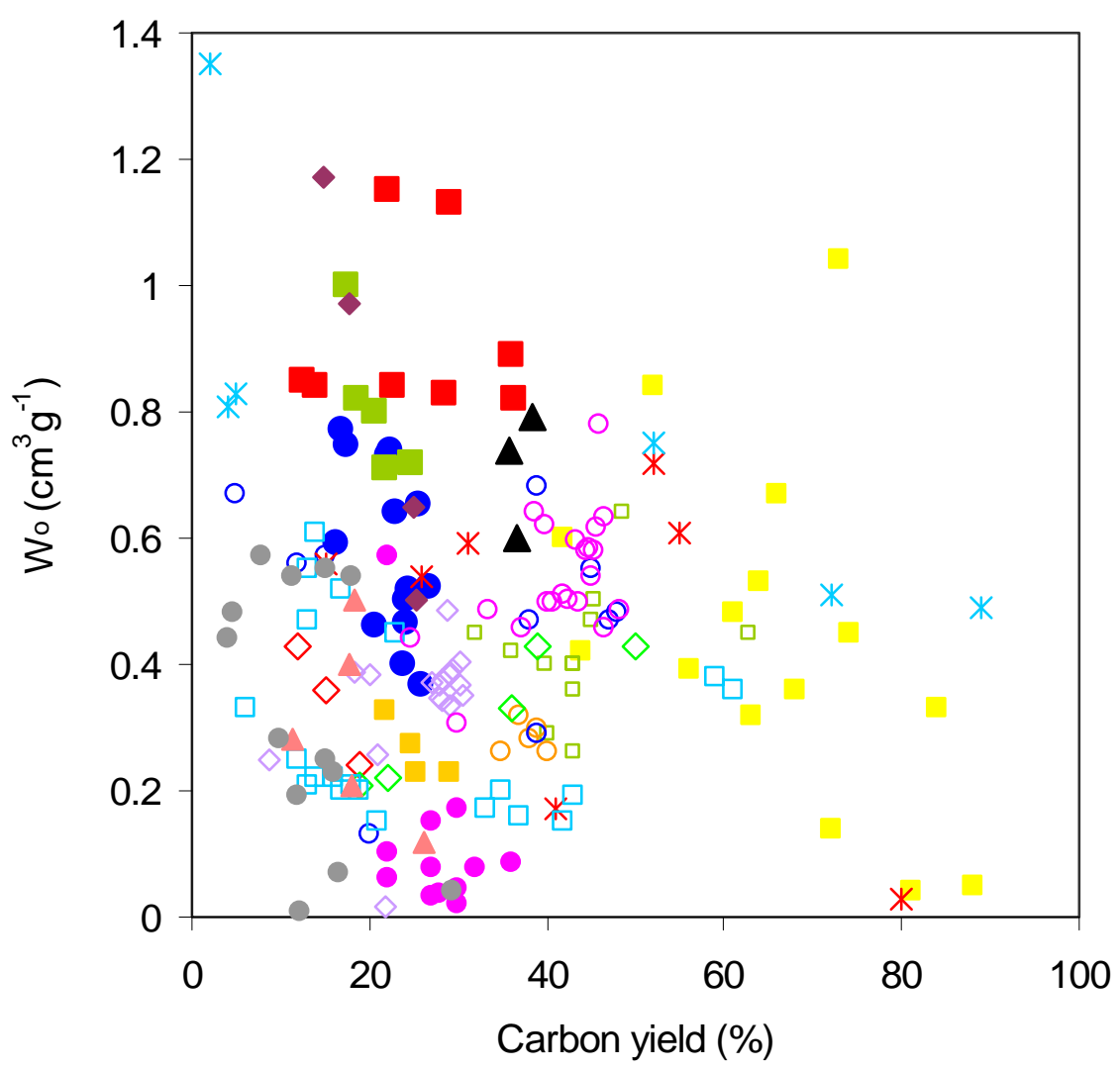


Figure 3.

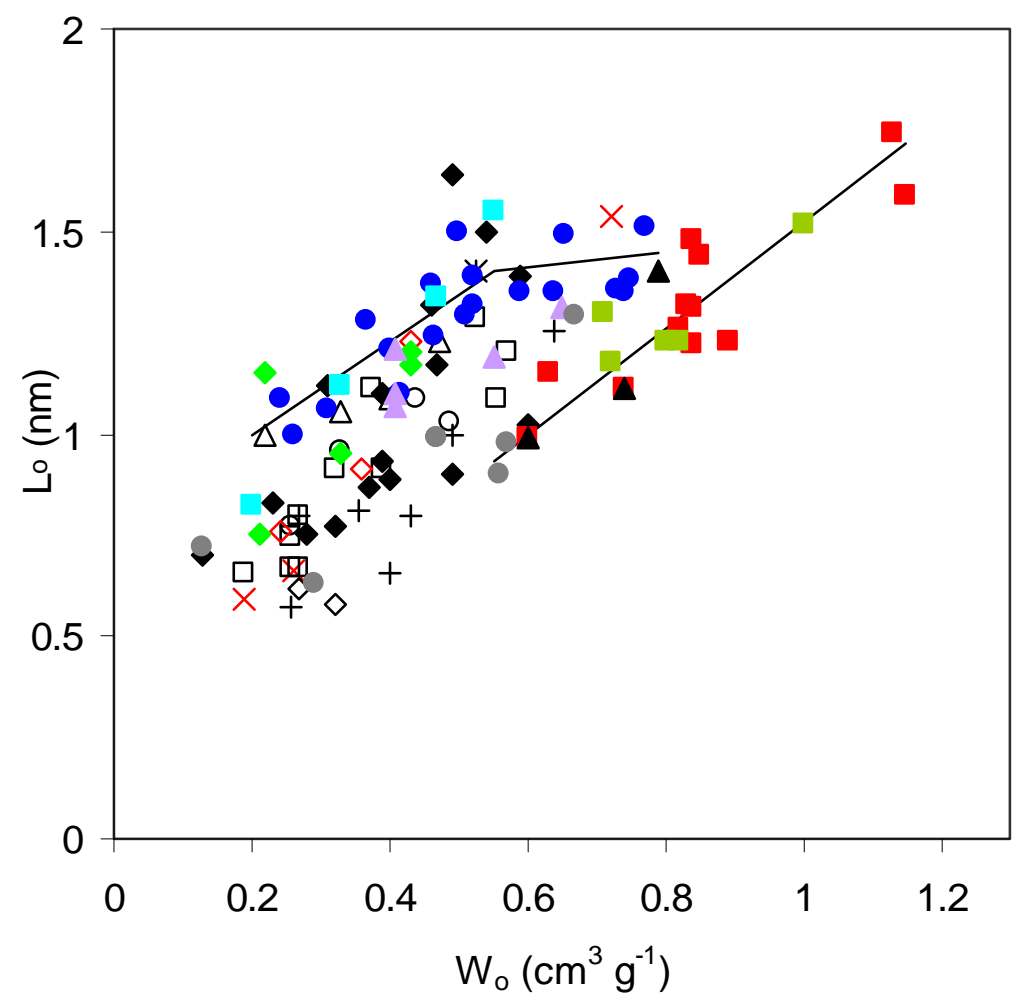


Figure 4.

(a)

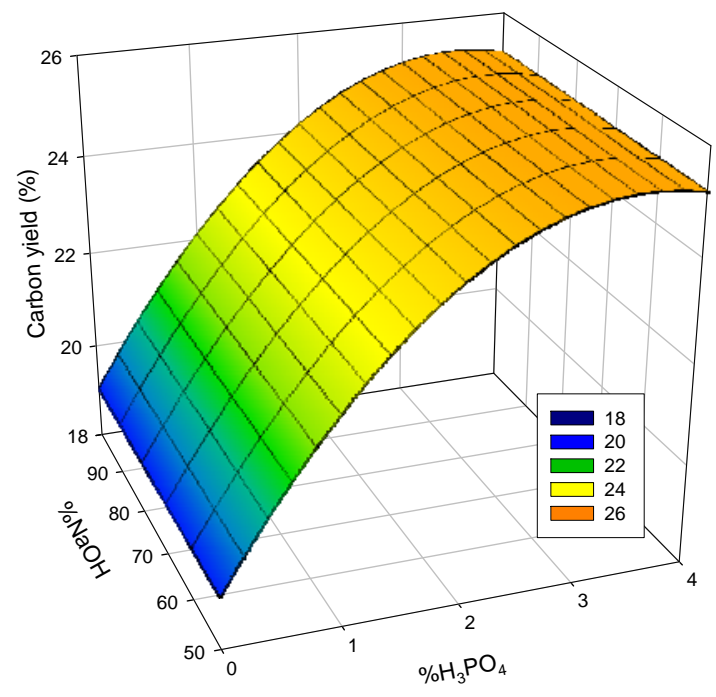

(b)

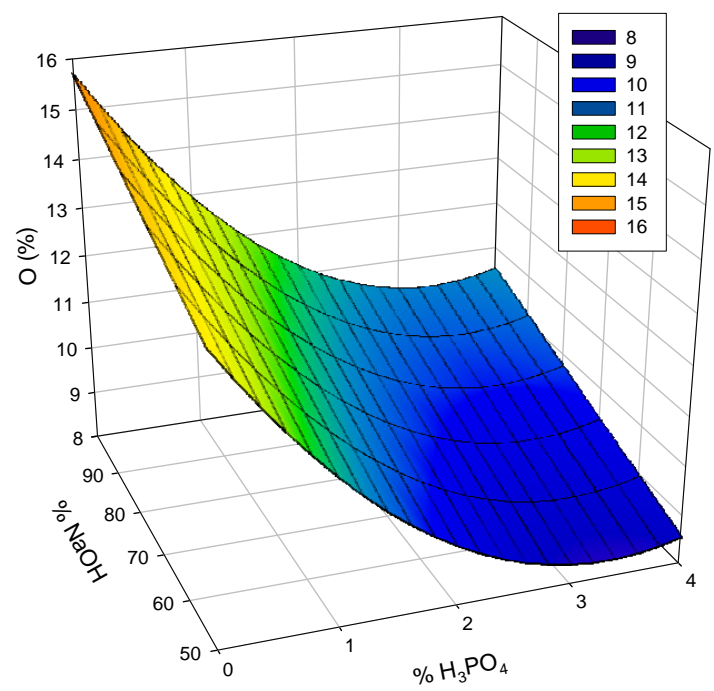

(c)

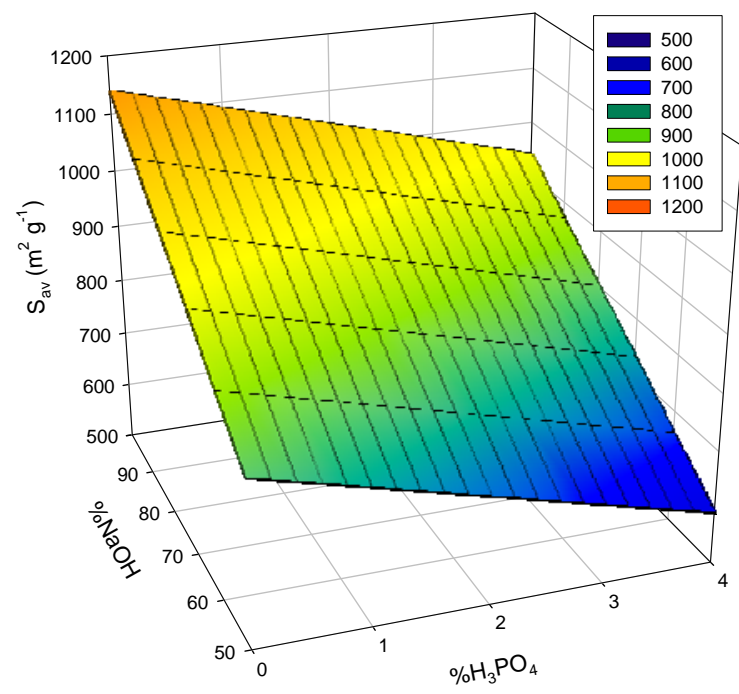


Figure 5.

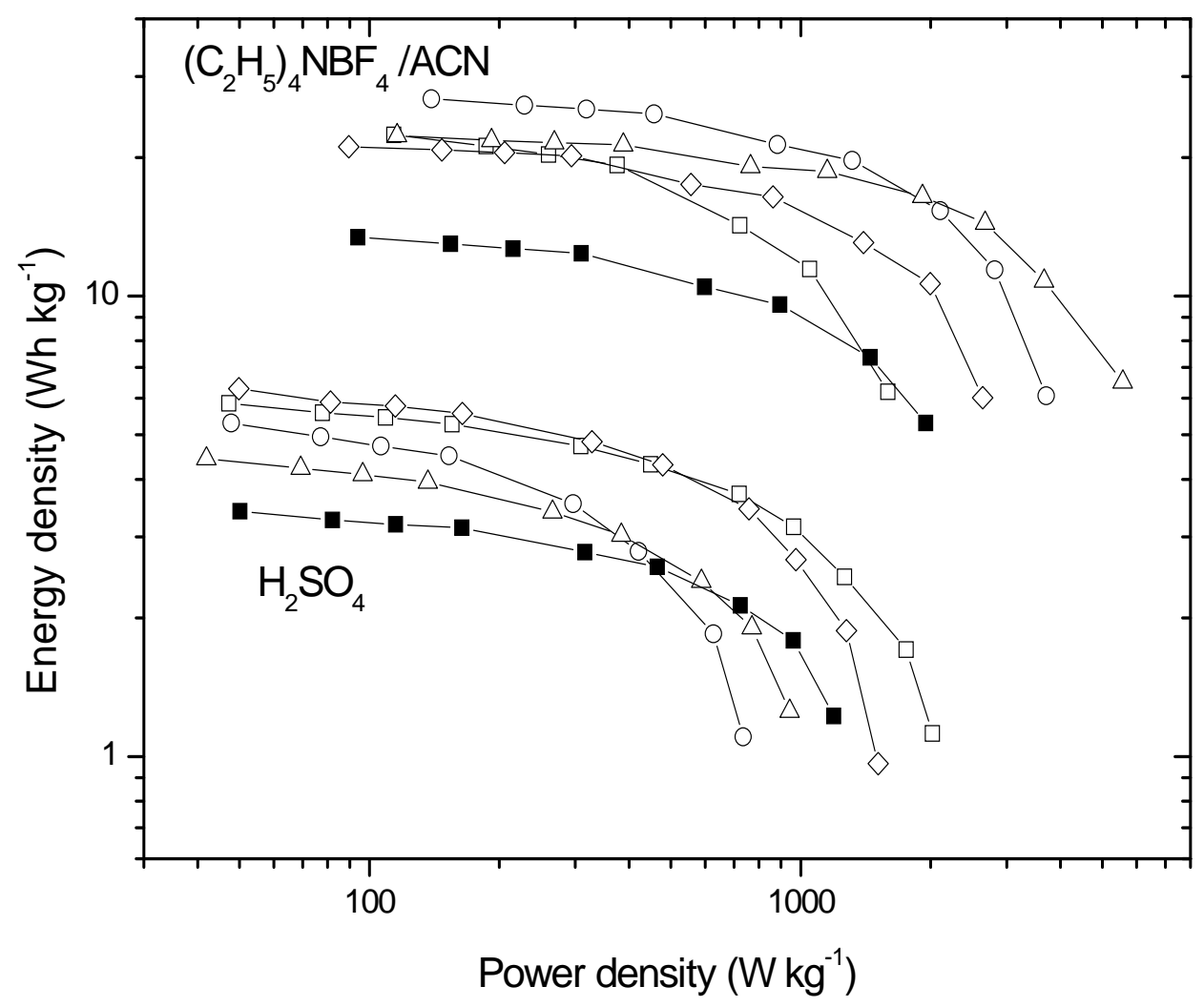

